towards the north-east, though it still extended from the southsouth-east to north-north-west. By 1 oh. $55 \mathrm{~m}$. it had broken up into four irregular streaks of clouds of various breadths and parallel to each other, the only portion of the original arch being a narrow streak extending from the south-east to the meridian, where it faded away. This was the "beginning of the end," for the remnant of the original arch and the other clouds in a short time d'sappeared below the eastern horizon, leaving the sky beautifully clear.

I should much like to know whether any other observer was fortunate enough to observe this remarkable clond; I say remarkable because, though $\mathrm{I}$ have been a pretty constant observer of the heavens for the last eight years, I have never noticed anything of the kind before.

Io, Malvern Road, Dalston, E., July 24

\section{Triple Rainbow}

IN the afternoon about 5.30 a week or ten days agn, I noticed a rainbow of the ordinary type, and quite complete, which lasted about five minutes; the portion to the right hand then faded away, as well as the upper and lower portions apparently of that fart of the bow visible to the left hand; but the middle portion of the remainder of the bow divided apparently into three parts, each one complete in their prismatic colouring, and yet none of them parallel to each other.

There was a slight difference in size, po:sibly in favour of that portion belonging to the original bow, and which constituted the outermost of the three arcs.

This portion of the phenomenon lasted $f(r$ about five minutes, and was also similarly observed by a gentleman walking with me at the time.

Unfortunately some large trees prevented us from seeing the lower portion of the three arcs, where presumably they should have been united into one.

Coles, Buntingford, Herts, July 23

\section{A Remarkable Meteor}

IN regard to the meteor seen by your correspondent P. F. D. at Hendon on the 6th inst., at 8.53 p.m., in a clear sky and broad daylight, I have the following entry in my diary under the same date : "Meteor going south-east through Cassiopeia at seven minutes to nine ; daylight." It was indeed a remarkable meteor. The sun had set about half an hour. I happened at the time to be looking intently at that part of the north-east sky in uhich it appeared. What struck me most was the brilliant sparkling silvery light given off by the fragments into which it divided just before disappearing. I estimated that it would strike the horizon about the south-east point.

Dulwich, July 21

\section{The Function of the Sound-Fost in the Violin}

MAY I be permitted to correct a careless expression in my letter appearing in your last issue on thi - subject? The passage I refer to is this: "If the bridge [of the viclin] were placed near one end of the instrument, the ca e would be different," i.e. the tone would be louder. I ought rather to have saicl : "If the hridge were placed nearer to a firm support, the case would be different." The statement is perfectly true as it stands with a sound-bcard which is equally thin all over, or where the edges are tbicker than the middle. It is not true with a construction like that of the violin, where the edges are extremely thin and flexible. A sonorous wave aluays transmits itself best from the stronger part of the surface to the weaker.

R. Howson

\section{Sand}

Mr. MELVIN is at fault in assuming that my paper on sand was "an attempt to distinguish by the aid of the micri score whether sand had been formed by the action of wind or of surf." Its primary object was to show that chalk-fint had scarcely any place in its formation; but few particles of it appearing even from the midst of rolled shingle whether that be ancient or modern. Other problems of course may be determined or solutions suggested by an extensive examination of ancient deposite, compared with those now forming. I have sbown that quartz is he great staple of "sand." The size of its particles, whether rounded by attrition or flat, rough, and angular, must be accounted for by observing the conditions under which it exists in modern formations. A large series is being examined by me, and a record will be made of the result. As yet I have iio theory whatever. I simply record facts. J. G. WALLER 68, Bolsover Street, W., July is

\section{ON MOUNTING AND PHOTOGRAPHING MICROSCOPIC OBJECTS}

WE have received from $\mathrm{Mr}$. E. Wheeler of Tollington Road, Holloway, a collection of mounted microscopic objects, comprising anatomical, botanical, entomological, and other preparations, and we have much pleasure in testifying to the general excellence of the work. One of the objects-a vertical section of the human small intestine-deserves special mention. It shows the glandular cells especially well. The nerves and ganglia of Auerbach's plexus can be seen, and inturspersed among the epithelial cells of the villi and Lieberkuhnian follicles are numerous goblet cells.

Space will not allow more than a bare mention of t:e other objects, including a large transverse section of the stem cf Lepidodendron from coal, transverse sections of the stems of spruce fir (Abies excelsa) and mare's tail (Hippuris vulgaris), the former showing resin canals and sections of bordered pits in the wood cells; Spirogyra in various stages of conjugation, from the first modification of the conjugating cells to the maturation of the zygospores; various Diatomaceæ, including the rare Coscinudiscus excavata; injected preparations of intestine of cat and toe of white mouse, and various entomological objects. They are all well prepared, and represent a stock which Mr. Wheeler informs us amounts to fifty thousand objects.

Although the legitimate use of professionally-mounted objects such as these may tend in no small degree to the diffusion of scientific knowledge, the microscopist who employs his instrument for no better purpose than the examination of bought slides will derive little benefit from the pursuit. He should be able to prepare objects for himself, and although there is abundance of accessible information on every detail of the art, it is believed that there is yet a useful work to be accomplished. By showing the facility with which this can be done without resort to the multiplicity of processes usually considered necessary, we shall endeavour in this article to show how any possessor of a microscope may make for himself preparations which, though they may not equal by many degrees the productions of the best professional mounters, yet have a far higher educational value, as their preparation will afford information which could not be otherwise acquired.

The necessary materials and instruments are few and inexpensive. For the support of the objects a supply of the usual $3^{\prime \prime} \times \mathrm{I}^{\prime \prime}$ glass slides with ground edges, and of thin cover glasses (preferably circular) of various sizes should always be at hand. These when bought will be dirty, and it saves time to clean them all at one operation.

For securing the cover to the slide various cements are used, but of these two only need be mentioned, as they will be sufficient for all ordinary purposes. Gold size is undoubtedly the most reliable cement, but it takes days or sometimes even weeks to harden. It is, however, exccedingly tenacious and tough, and does not become brittle with age. It should always be used in cases where objects are mounted dry or in liquid, but when viscid media are employed, the medium helps to secure the cover, and there is no danger of leakage. Under these circumstances the use of asphalte varnish is recommended. The Brunswick black of the oilshops is a common form of this varnish, but is not so good as the preparation supplied by the opticians. When the varnish is to be used, it must be warmed by standing it in a cup 